\title{
Concentration of nitric oxide in patients' saliva from various metal restorative activities in the oral cavity
}

\author{
Enes Pašić ${ }^{1}$, Amira Dedić ${ }^{1}$ Jasminko Huskić ${ }^{2}$, Sanja Hadžić ${ }^{1}$
}

${ }^{1}$ Department for Periodontology and Oral Medicine, Faculty of Dentistry in Sarajevo, University of Sarajevo ${ }^{2}$ Institute for Medical Physiology and Biochemistry, Faculty of Medicine in Sarajevo, University of Sarajevo Bosnia and Herzegovina

Corresponding author: Enes Pašić Department for Periodentology and Oral Medicine Faculty of Dentistry Bolnička 4a 71000 Sarajevo Bosnia and Herzegovina epasic@sf.unsa.ba Tel.: + 38733214249 Fax: + 38733443395

Received: 18 October 2011 Accepted: 10 November 2011

\section{Copyright (c) 2011 by}

Academy of Sciences and Arts of Bosnia and Herzegovina. E-mail for permission to publish: amabih@anubih.ba
Objective. The aim of this paper is to determine the concentration of nitric oxide $(\mathrm{NO})$ in the saliva of subjects resulting from the presence of various metal restorative activities in the oral cavity. Patients and methods. The research was conducted on 20 subjects ( 12 women and 8 men), aged 18-30, with no metal fillings in their oral cavity and 20 subjects (11 women and 9 men) aged 18-30 with prosthetic and conservative work in their oral cavities made of various metals. The $\mathrm{pH}$ of the saliva was established by means of an "Orion" type $\mathrm{pH}$ meter at an optimal temperature of $25^{\circ} \mathrm{C}$. The concentration of NO was determined by conversion of $\mathrm{NO}_{3}^{-2}$ into $\mathrm{NO}_{2}^{-2}$ with the help of elementary zinc and then by colorimetric testing of the $\mathrm{NO}_{2}^{-2}$ concentration by means of the Griess reagent. Results. Our results established that the concentration of NO in patients with various metals $(60.18 \pm 10.24)$ is $33.7 \%$ higher, which is statistically insignificant, in relation to the control group (45.01 \pm 6.28$)$. Conclusion. Various metal restorative activities stemming from dentistry practice do not cause changes in the $\mathrm{pH}$ values of saliva and $\mathrm{NO}$ concentrations.

Key words: Saliva, Nitric oxide, Various metals.

\section{Introduction}

Nitric oxide (NO) acts as a biological messenger in the organism. NO is a short-lived gas that acts as a free radical since it contains an extra electron that enables high chemical reactivity (1). Recent evidence indicates the favourable anti-microbe effects of NO in the oral cavity (2). In the organism, NO acts as a physiological and pathophysiological mediator (3). The physiological roles of NO are numerous. NO participates in the vasodilatation of the soft muscles in the blood vessels, and inhibits the aggregation and adhesion of thrombocytes. It acts as a neuronal messenger and participates in the regulation of the immune response (4). NO plays an anti-bacteriolog- 
ical role, inhibits the growth of bacteria and increases the macrophage cytotoxic mechanism. It easily penetrates the cell membrane, causes damage to bacteria, virus and tumour cells by means of mechanisms for the inhibition of the DNA synthesis (5).

The supragingival plaque, rich with anaerobe and aerobe flora, leads to a significant increase of oral NO (6). The current results support the thesis of $\mathrm{NO}$ as a modulator of bacterial proliferation and suggest that increased NO may contribute to a lower incidence of caries (7). Rehar et al. (6) have proved that the level of NO in the saliva of a patient with a generalised chronic periodontitis is increased and that NO can be regarded as a potential biological marker for detecting and monitoring the illness. The level of NO in the saliva of a smoker has been proven to be lower. The smoke components from a cigarette cause impairment of cells and reduce the cellular production of NO (8). There is clear evidence of lower concentrations of $\mathrm{NO}$ in patients who have used a wide spectrum of antibiotics in relation to those subjects who have not used antibiotics (9). NO is related to xerostomia, as the higher concentration of NO leads to the impairment of the salivary acinus. A change in the concentration of $\mathrm{NO}$ in saliva was noted in patients with diabetes mellitus, blood dyscrasia, autoimmune diseases and other diseases with xerostomia as one of the diseases symptoms. Dry mouth as a clinical symptom, with the consequent physiological, biochemical and immunological deficiency of the saliva's defensive function, contributes to an increased occurrence of periodontal and oral infections (10).

The $\mathrm{pH}$ values in the saliva affect the concentration of NO. Reductions of NO have been established in cases of decreased $\mathrm{pH}$ values (11). The oral cavity is moist and exposed to temperature changes, $\mathrm{pH}$ changes, and frequent changes of the chemical com- position of the saliva, which favour the reaction of various metals in the mouth.

Various metals, with various electro-potentials, generate a galvanic cell through the saliva as electrolytes. The power of the micro-galvanic currents depends on the saliva or its compositions, $\mathrm{pH}$, the surface voltage and the buffer capacity. The power of the galvanic cell also depends on the potential of the metal. If the difference in the potential is higher, the galvanic damage will be of higher intensity.

The aim of this paper is to determine the concentration of nitric oxide (NO) in the saliva of subjects resulting from the presence of various metal restorative activities in the oral cavity.

\section{Patients and methods}

The sample selection process was initiated on the grounds of the set aim. The research was conducted on 40 subjects divided into 2 groups. On the basis of subjective and objective indicators of their general health, none of the examinees had any manifestations of clinical or pathophysiological changes and were not taking medications which could affect the concentration of NO in the saliva. Control group - 20 subjects (12 women and 8 men), aged 18-30 years with no metal fillings in their oral cavity. Experimental group - 20 subjects (11 women and 9 men) aged 18-30 years with prosthetic and conservative work made of various metals.

The research was conducted on the grounds of a common approach to the examinees by analysing their medical history, an objective clinical examination and lab tests. After rinsing the mouth for one minute in order to remove debris and reduce the number of microorganisms, $2 \mathrm{ml}$ of non-stimulated saliva was gathered into two sterile test tubes. The concentration of $\mathrm{NO}$ was determined by means of the conversion of $\mathrm{NO}_{3}^{-2}$ into $\mathrm{NO}_{2}^{-2}$ with the help of elementary zinc and then 
by measuring the concentration of $\mathrm{NO}_{2}^{-2}$ by using the Griess reagent. After ten minutes of mixing in a vibrator at room temperature, the absorption of light (optical density) was measured by a spectrophotometer with a $545 \mathrm{~nm}$ filter. The concentration of nitrite was sensed from the standard curve with a known concentration of $\mathrm{NaNO}_{2}(1.56-$ $100 \mathrm{~nm}$ ). The distilled water, with a Griess reagent added, was used for a blind trial. The $\mathrm{pH}$ of the saliva was established by an "Orion" type $\mathrm{pH}$ meter at an optimal temperature of $25^{\circ} \mathrm{C}$. To measure the galvanic micro-current, a digital VOLTCRAFT VC 140 multi-meter was used.

\section{Statistical analysis}

The results were statistically processed and the mean value was established for each group, together with the standard deviation, the standard error of mean and values in percentage. A Student's t-test was used to determine the statistical significance of the mean values of the established parameters. The values $\mathrm{p}<0.05$ were taken as significant.

\section{Results}

The results from analysing the values of the subjects' $\mathrm{pH}$ values in the saliva by groups are presented in Figure 1.

The results indicated that the mean value of the $\mathrm{pH}$ in the saliva of the subjects from the experimental group $(6.89 \pm 0.09)$ was reduced by $1.43 \%$ in relation to the subjects from the control group $(6,99 \pm 0,07)$ but this was not statistically significant.

The mean values of the $\mathrm{pH}$ in the saliva in the analysed groups by gender are presented in Figure 2.

The statistical analysis shows that no statistically significant difference by gender was established in the values of the $\mathrm{pH}$ of the saliva in the examined groups.

The mean values of the NO concentration in the saliva of the subjects from the analysed groups are presented in Figure 3.

The results established that the mean values of NO in patients with various metals in their oral cavity $(60.18 \pm 10.24)$ are $33.7 \%$ higher, which is however statistically insignificant, in relation to the control group (45.01 \pm 6.28$)$.

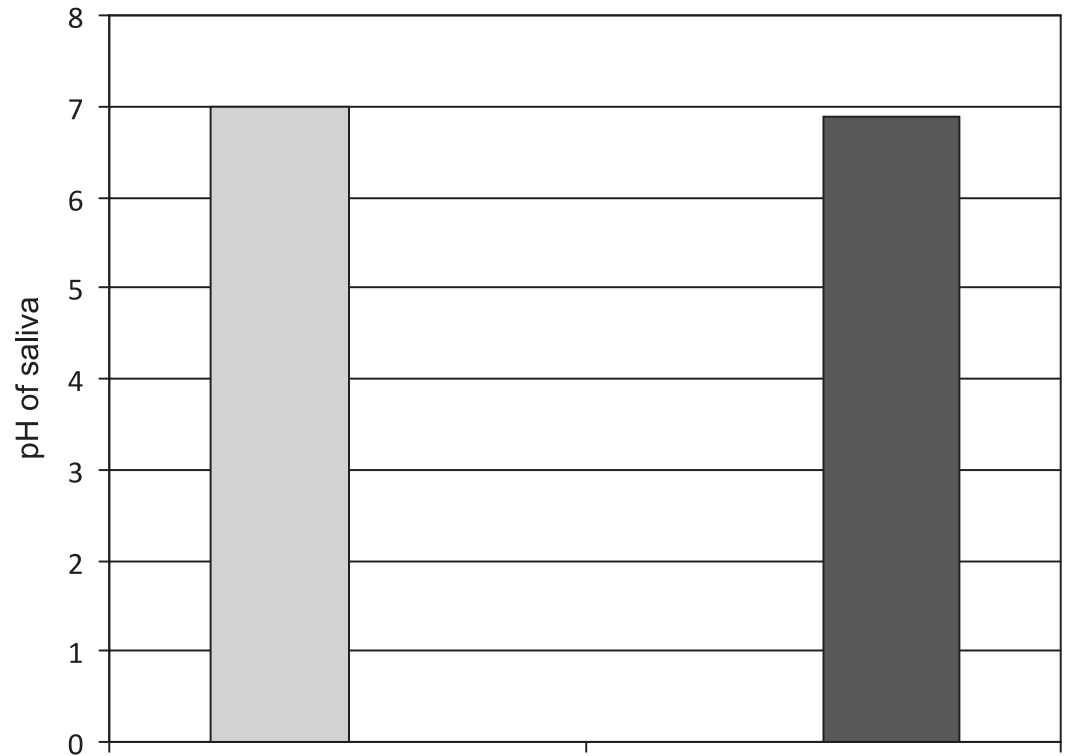

Figure 1 Mean values of the subjects' $\mathrm{pH}$ in saliva by groups $\square$ Control group

Experimental group 


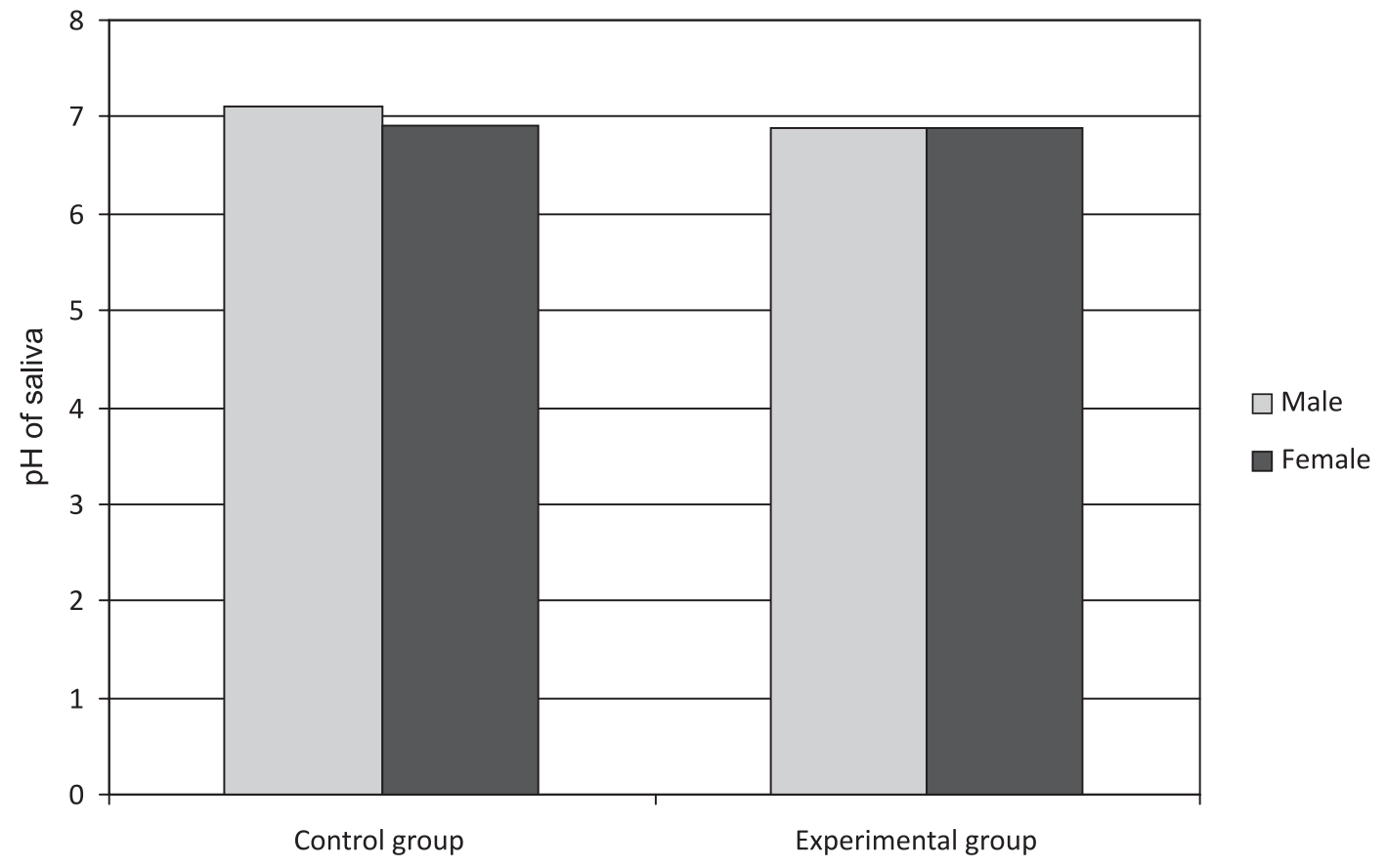

Figure 2 Gender differences in the mean values of the $\mathrm{pH}$ in the saliva of the subjects

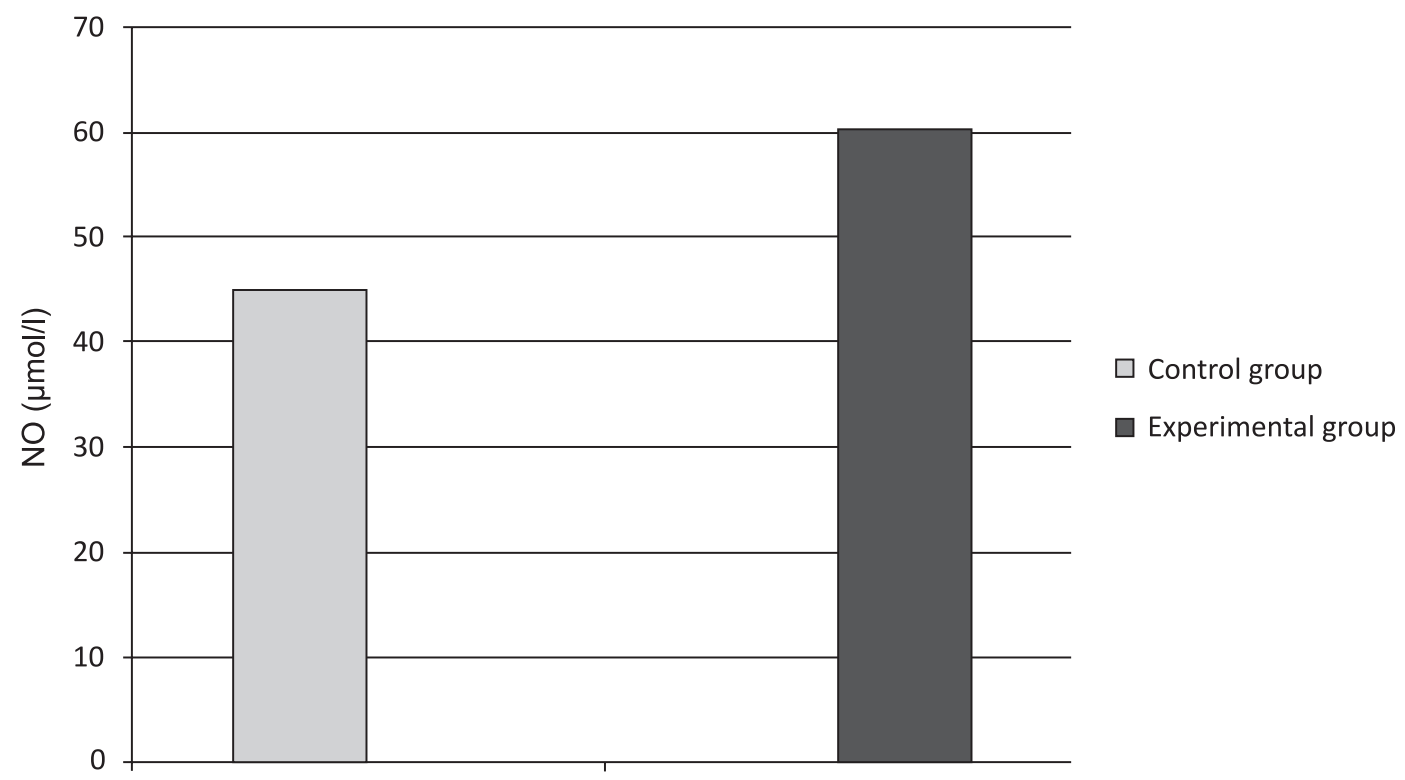

Figure 3 Mean values of NO concentration in the saliva of the subjects

The mean values of the NO concentration in the saliva of the subjects distinguished by gender are presented in Figure 4.
The statistical analysis shows that no statistically significant difference by gender was established in the concentration of $\mathrm{NO}$ in the saliva in the examined groups. 


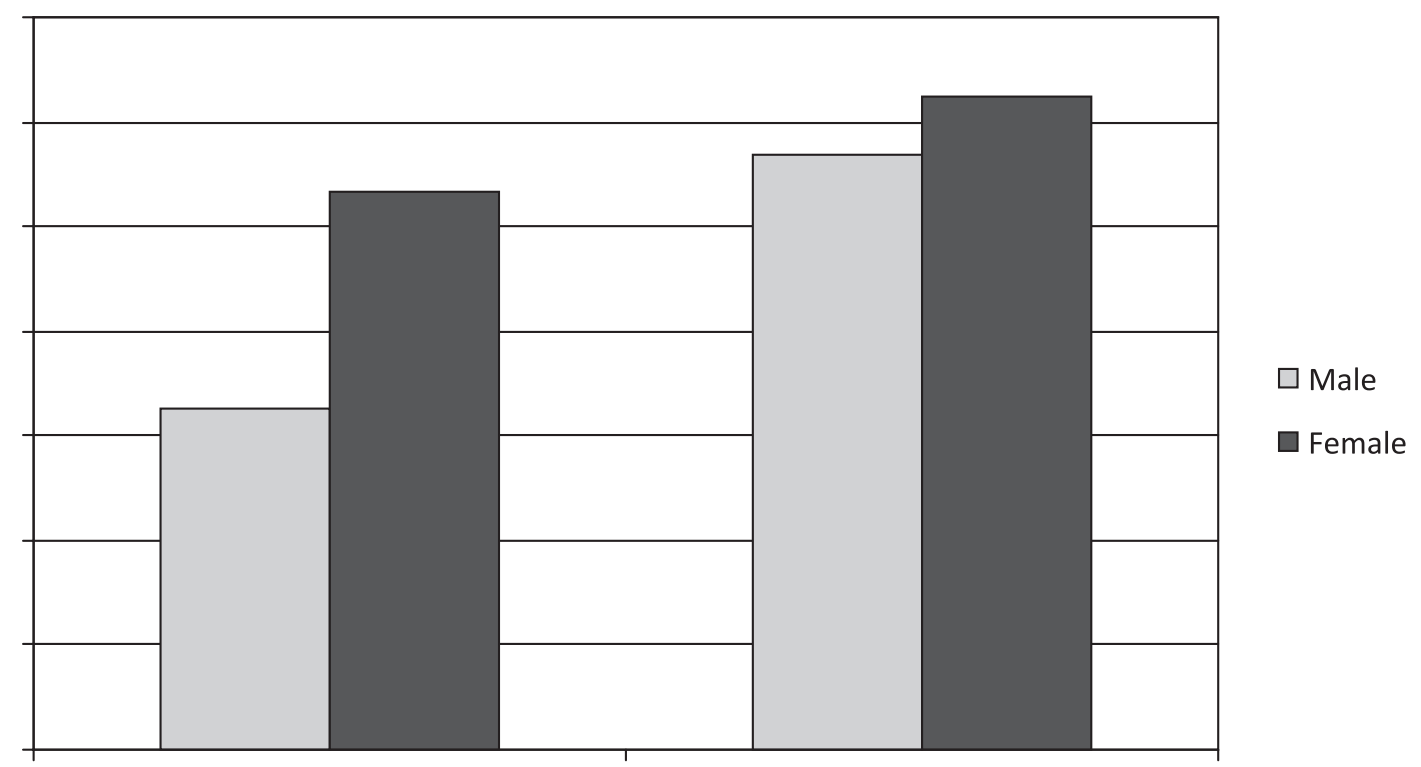

Figure 4 Gender differences in the mean values of the concentration of NO in the saliva of the subjects

\section{Discussion}

NO is a topic of interest amongst various scientific groups in view of the fact that it performs various physiological and pathophysiological processes in the organism. Many authors have confirmed the effects of NO on the vasodilatation of the cerebral, coronary, pulmonary, renal and musculoskeletal circulation $(1,3,12)$. NO enters the saliva through nerve fibres, capillary endothelium and macrophage and can also be synthesised in the salivary gland acinus. The NO modifies the concentration of $\mathrm{Ca}^{+2}$ in the salivary cell where it is synthesised and moves onto the surrounding tissues through simple diffusion (13). NO plays an anti-bacteriological role, inhibits the growth of bacteria and increases the macrophage cytotoxic mechanism. As a strong reactive radical, NO participates in the non-specific defensive mechanisms of the oral cavity, which is linked to the significant immunological potential of NO in the saliva of our subjects.

Our research has shown that the values of the NO concentration in the saliva of the subjects with various metal restorative work are higher than in those in the control group but this is not statistically significant. The difference between the values of NO in the subjects' saliva distinguished by gender is not statistically significant.

Our results regarding the values of $\mathrm{NO}$ concentration in the saliva of the subjects with various metal restorative work in their oral cavity can be justified by the small sample (20 subjects) and the young age group (18-30 years old) of the examinees, who did not have systemic diseases and pathophysiological changes in their oral cavities.

In our research, the $\mathrm{pH}$ values in the saliva of the subjects from both the control and the experimental group were neutral. The subjects did not have systemic diseases, periodontal inflammation or salivary secretion disorders, which would affect the concentration of $\mathrm{NO}$ and the $\mathrm{pH}$ values of saliva (10).

The concentration of NO in our research was higher in the middle of the neutral $\mathrm{pH}$ value of the saliva, which corresponds to the research conducted by Palmerini (11) who attested that the concentration of $\mathrm{NO}$ is 
higher in the middle of the neutral $\mathrm{pH}$ values of saliva.

Differences by gender in the $\mathrm{pH}$ values of saliva in the experimental and control groups were not statistically significant.

The $\mathrm{pH}$ value of saliva is important for the release of ions originating from various metal prosthetic and conservative work. Ankea et al. (14) have verified that the release of ions of cobalt, chrome, iron, nickel and zinc from analysed alloys depended on the time of the alloy exposition to phosphate buffer $\mathrm{pH}$ 6.0. This data is important since cobalt-chrome-molybdenum alloy, which is most commonly used as material for making skeletal prosthesis, has been found in the oral cavity of patients for very many years.

Moreover, Wataha (15) claims that the period of the presence of dental alloys in the oral cavity is an important factor in the intensity of ion release. In our research, various metal restorative work did not cause changes in the $\mathrm{pH}$ values of the saliva.

Karov et al. (16) indicate that the galvanised micro-current can cause prickling, burning, paraesthesia and pain. Baričević et al. (17) have shown in their paper that burning mouth syndrome was more frequent in patients with dental metals but there was no correlation between high concentrations of nickel and chrome in the saliva and burning mouth syndrome.

We did not verify subjective symptoms of prickling, higher or lower intensity of burning and metallic taste in our patients with various metal restorative work in their oral cavities, which is not in compliance with the research conducted by Karov (16).

The subjects from the experimental group had had their various metal prosthetic and conservative work for one year and we thus deem that this short time period was insufficient for any consequences caused by oral galvanism.

Our results cannot be compared with the results of other researchers since we have not come across data on the physiological and immunological mechanisms of $\mathrm{NO}$ in the saliva in the presence of various metal restorative work in the oral cavity.

Considering that we have only examined the presence of various metals, we believe that it would be interesting to explore the level of NO in the saliva compared to the number of various conservative and prosthetic metal solutions (metal fillings, crowns, and mobile prosthetics), and the time they are present in the oral cavity.

Technological procedures have, so far, not confirmed an alloy which would be completely stable in the organism, and which would show no signs of biodegradation.

In stomatology it is recommendable to use alloys with a known composition and good biocompatibility. Precise technological procedures in the laboratory are an important precondition for the prosthetic treatment of patients.

The role and the importance of NO and its metabolites, as well as the effect of various factors on the concentration of NO in the saliva of patients with various metal prosthetic and conservative works are dilemmas which can be used as subjects of further research.

\section{Conclusion}

The values of the NO concentration in the saliva of the examinees with various conservative and prosthetic metals in their oral cavity are higher but the difference is is not statistically significant in relation to the control group. The variations in the mean value of the NO concentration in the saliva of examinees distinguished by gender do not have statistical significance in either group. The various metal restorative works in our patients have not affected the changes to the $\mathrm{pH}$ values of the saliva.

Conflict of interest: The authors declare that they have no conflict of interest. This study was not sponsored by any external organisation. 
Authors' contributions: Conception and design: EP and $\mathrm{JH}$; Acquisition, analysis and interpretation of data: JH, EP and AD; Drafting the article: EP and SH, Revising it critically for important intellectual content: $\mathrm{EP}, \mathrm{JH}$ and $\mathrm{AD}$.

\section{References}

1. Moncada S, Palmer RMJ, Higgs EA. Nitric oxide: Physiology, pathophysiology and pharmacology. Pharmacological review. 1991;43(2):109-34.

2. Krishnan R. Nitric oxide-Friend, basic sciences. Proceedings of a Symposium conducted by the Dept Of Physiology. Calicut Medical College on 13th February 1999.

3. Michel T, Feron O. Nitric oxide synthesies which, where, how and way? Clin Invest. 1997;100:2446-52.

4. Moncada S, Higgs EA. Endogenous nitrc oxide: physiology, pathology and clinical relevance. Eur J Clin Invest. 1991;31:361-74.

5. Carossa S, Pera P, Doglio P, Lombardo S, Colagrande P, Brussino L, Rolla G, Bucca C. Oral nitric oxide during plaque deposition. European Journal of Clinical Investigation. 2001;31:876-9.

6. Reher VG, Zenóbio EG, Costa FO, Reher P, Soares RV. Nitric oxide levels in saliva increase with severity of chronic periodontitis. J Oral Sci. 2007;49(4):271-6.

7. Šrdilović D, Stojanović I, Apostolović M. Salivary nitric oxide as biomarker of caries risk in children. Acta Stomatologica Croatica. 2009; 43(1):39-44.

8. Bodis S, Haregewoin A. Significantly reduced salivary nitric oxide levels in smokers. Annals of oncology. 1994;5:371-72.
9. Dougal T Hamish, Smith L, Duncan C, Nigel B. The effect of amoxycilin on salivary nitrite concentrations: an important mechanism of adverse reactions? Br J Clin Pharmac. 1995;35:460-2.

10. Konttinen HK, Platts LA, Eukland KK, Santavirta N, Tornwall J, Sorsa T. Role of nitric oxide in Sjögren syndrome. Arthritis Rheum. 1997;40(5):875-83.

11. Palmerini CAS, Palombari R, Perieto S, Arienti G. NO synthesis in human saliva. Free Radic Res. 2003;37(1):29-31.

12. Radegran G, Saltin B. Nitric oxide in the regulation of vasomotor tone in human sceletal muscule. Am J Physiol. 1999;276:1951-60.

13. Tritsaris K, Looms DK, Nauntofte B, Dissing S. Nitric oxide synthesis causes inositol phosphate production and $\mathrm{Ca} 2+$ release in rat parotid acinar cells. Pflugers Arch. 2000;440:233-8.

14. Anke M, Glei M, Muler R, Dorn W, Vorman J, Anke S. Macro, trace and ultratrace element intake of adults in Europe: problems and dangers? J Commodity Sci. 2000;39:119-39.

15. Wataha JC, Lockwood PE. Release of elements from dental casting alloy into cell-culture medium over 10 month. Dent Mater. 1998;14:158-63.

16. Karov J, Hinberg I. Galvanic corrosion of selected dental alloys. J Oral Rehabil. 2001;28(3):212-9.

17. Baričević M, Mravak-Stipetić M, Stanimirović A, Lončar B, Andabak A, Baričević D. Salivary concentrations of nickel and chromium in patients with burning mouth syndrome. Acta Dermatovenerol Croat. 2011;19(1):2-5. 